\title{
Pengukuran Kinerja Perusahaan Jasa Transportasi Niaga Darat Menggunakan Metode Baldrige Excellence Framework (Studi Kasus pada PT. Galena Perkasa Sidoarjo)
}

\author{
Dwi Indra Prasetya ${ }^{1^{*}}$, Fourry Handoko ${ }^{2}$, Prima Vitasari ${ }^{2}$ \\ ${ }^{1}$ Program Studi Magister Teknik Industri, Institut Teknologi Nasional, Malang, 65145, Indonesia \\ ${ }^{2}$ Pascasarjana, Jurusan Teknik Industri, Institut Teknologi Nasional, Malang, 65145, Indonesia \\ *E-mail : din.prasetya74@gmail.com
}

\begin{abstract}
Abstrak
Ketatnya persaingan usaha di era globalisasi ini, mengharuskan pelaku usaha untuk terus memperbaiki kinerjanya, tidak hanya meningkat tapi sebisa mungkin unggul (excellence), tidak terkecuali usaha di bidang jasa transportasi niaga darat (land freight forwarder). Berdasarkan laporan keuangan selama tiga tahun terakhir, menunjukkan tren kinerja keuangan perusahaan cenderung menurun. Hal ini disebabkan oleh banyak faktor, baik secara eksternal maupun internal perusahaan. Hasil observasi di lapangan membuktikan penyebab penurunan kinerja keuangan lebih didominasi oleh faktor internal. Untuk proses perbaikan internal, diperlukan langkah awal pengukuran pencapaian kinerja saat ini. Dikarenakan saat ini perusahaan tidak mempunyai alat ukur kinerja secara menyeluruh dan berorientasi kinerja unggul (performance excellence), maka metode pengukuran kinerja pada penelitian ini menggunakan alat ukur berbasis Baldrige Excellence Framework kriteria Bisnis. Selain hasil observasi, instrumen utama penelitian ini adalah hasil survei kuesioner terhadap karyawan perusahaan. Berdasarkan hasil survei kuesioner didapatkan tingkat pencapaian kinerja berbasis Baldrige Excellence Framework kriteria Bisnissaat ini sebesar 750 poin dengan prosentase pencapaian secara keseluruhan sebesar 74\% yang artinya perusahaan berada pada tingkat Pemimpin Bisnis (Business Leader) dengan kategori Unggulan (Excellent).
\end{abstract}

Kata kunci : alat ukur kinerja, Balridge Excellent Framework,kinerja unggul.

\section{Pendahuluan}

PT. Galena Perkasa Sidoarjo (perusahaan) adalah perusahaan perorangan yang bergerak dalam bidang usaha jasa transportasi niaga darat, yang telah 23 tahun berkecimpung di dunia transportasi niaga darat. Sebagai bagian dari rantai pasok nasional, maka sudah menjadi kebutuhan dan kewajiban perusahaan untuk ikut serta mendukung program pemerintah akan penguatan dan peningkatan kualitas tenaga kerja. Di samping itu, berdasarkan laporan keuangan selama periode 2016-2018 terjadi penurunan kinerja keuangan dikarenakan oleh beberapa faktor, baik eksternal maupun internal. Faktor eskternal diantaranya disebabkan oleh turunnya jumlah permintaan kendaraan oleh konsumen dan kompetisi ketat dengan pihak kompetitor. Sedangkan faktor internal diantaranya adalah naiknya angka claim barang rusak (damage goods) akibat pengiriman, kecelakaan kendaraan, sistem perawatan dan perbaikan kendaraan tidak berjalan optimal, serta proses penagihan dan pengembalian surat jalan konsumen (Purchase of Delivery return) yang tidak sesuai ketentuan. Berdasarkan observasi dipastikan penyebab utama faktor internal di atas adalah turunnya kinerja tenaga kerja.

Kinerja adalah proses membandingkan dalam periode tertentu antara sesuatu yang dihasilkan organisasi terhadap standar yang ditetapkan dan riwayatsebelumnya, secara terukur dan mampu menggambarkan kondisi empirik organisasi. Sebelum melakukan peningkatan kinerja, perlu mengetahui 
pencapaian kinerja saat ini dengan cara pengukuran kinerja. Sehingga penilaian kinerja mengandung makna suatu proses penilaian pelaksanaan kemampuan kerja suatu organisasi berdasarkan standar tertentu ${ }^{[1]}$.

Baldrige Excellence Framework (BEF) adalah alat ukur kinerja yang bersifat menyeluruh, dengan standarisasi internasional, dengan konsep kinerja unggul (excellence), dan mempelajari hubungan antara variabel bebas terhadap variabel terikat, terdiri atas enam variabel bebas yaitu Kepemimpinan, Strategi, Pelanggan, Pengukuran-Analisa-Manajemen Pengetahuan, Tenaga Kerja, dan Operasi serta satu variabel terikat Kinerja. Terhadap hasil survei kuesioner selanjutnya diberikan pembobotan-pembobotan dan perhitungan tertentu, agar hasil akhir diperoleh nilai pencapaian kinerja perusahaan saat ini ${ }^{[2]}$.

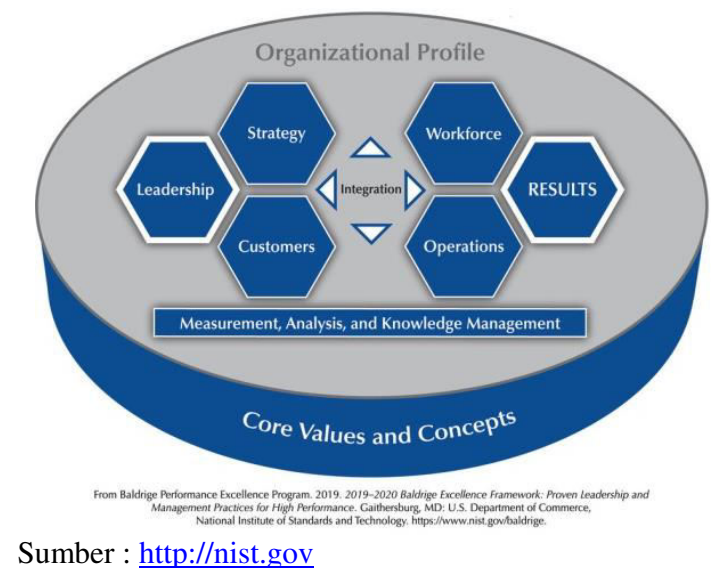

Gambar 1. Nilai dan Konsep Inti BEF.

Dasar pemilihan metode BEF untuk penelitian ini adalah bahwa pengukuran dilakukan di internal perusahaan dan secara data, bisa bersinergi dengan alat ukur kinerja lain sejenis, misal Balanced Scorecard, Lean Thinking, dan Six Sigma ${ }^{[3]}$. Untuk identifikasi dan operasionalisasi variabel penelitian ini menggunakan variabel bebas Kepemimpinan $\left(X_{1}\right)$, Strategi $\left(X_{2}\right)$, Pelanggan $\left(X_{3}\right)$, Pengukuran-Analisa-Manajemen Pengetahuan $\left(\mathrm{X}_{4}\right)$, Tenaga Kerja $\left(\mathrm{X}_{5}\right)$, dan Operasi $\left(\mathrm{X}_{6}\right)$ serta satu variabel terikat Kinerja (Y).

\section{Tujuan Penelitian}

Ada banyak penelitian sebelumnya tentang pengukuran kinerja dengan menggunakan alat ukur kinerja berbasis kriteria BEF, diantaranya:

1. Susanto, Edi (2017). "Analisis PendekatanMalcolm Baldrige Criteria for Performance Excellence $(M B C f P E)$ Terhadap Kinerja di PT. Kinenta Indonesia" "[4].

2. Kosasih, Wilson., Laricha, dan Hendrawan (2015). "Analisis Sistem Manajemen Mutu dengan Malcolm Baldrige National Quality Award di Perusahaan Global berstandar ISO 9001: 2008 (Studi Kasus: PT. Zebra Asaba Industries)"[5].

3. Kuspijani, DR.Ir. Indung Sudarto, MT. (2012). "Pengukuran Kinerja Fakultas Teknik Universitas Bhayangkara Surabaya (Ubhara) dengan Menggunakan Kriteria Malcolm Baldrige" ${ }^{\prime[6]}$.

4. Jayamaha, Nilal Palitha. Nigel P. Grigg dan Robin S. Mann. (2011). "Empirical Analysis of TheBaldrige Criteria as OrganizationalPerformanceMeasureand a TheoreticalModel ${ }^{,[7]}$.

Dengan pertimbangan di atas, maka disusunlah tujuan penelitian ini adalah untuk mengukur kinerja PT. Galena Perkasa Sidoarjo saat ini dengan menggunakan kriteria Baldrige Excellence Framework. 


\section{Metode Penelitian}

Penelitian ini menggunakan instrumen yang terdiri atas data yang disediakan perusahaan, hasil observasi, dan hasil survei kuisioner. Dalam perumusan kuisioner disusunlah butir-butir pertanyaan tertentu yang ditujukan kepada responden. Responden berdasarkan kriteria BEF adalah semua karyawan perusahaan yang dianggap mengetahui kondisi dan permasalahan yang ada saat ini di perusahaan. Butirbutir pertanyaan kuisioner merepresentasikan semua variabel $\mathrm{BEF}$, terdiri atas enam variabel bebas dan satu variabel terikat. Terhadap hasil survei kuisioner, dilakukan uji instrumen untuk mengetahui validitas dan reliabilitas masing-masing butir-butir pertanyaan. Dan sesudahnya dilanjutkan dengan proses pembobotan hasil survei kuisioner berdasarkan metode BEF kriteria Bisnis. Pembobotan ini diperlukan agar diketahui skor akhir dan prosentase pencapaian keseluruhan variabel, agar tingkat pencapaian kinerja perusahaan saat ini bisa diketahui.

\section{Populasi dan Sample}

Populasi penelitian adalah semua karyawan perusahaan yang berjumlah 70 orang. Dikarenakan jumlah populasi kurang dari 100 orang, maka sesuai teori, sample penelitian sama dengan populasi penelitian ${ }^{[8]}$.

\section{Pengumpulan Data}

Pengumpulan data adalah proses pengumpulan data yang dibutuhkan dalam penelitian ini, meliputi data sekunder dan data primer, yang akan dijelaskan di sub bab berikut di bawah ini.

Data sekunder adalalah data yang disediakan oleh pihak perusahaan, baik berupa tabel maupun gambar, yang terdiri atasprofilperusahaan, visi misi, struktur organisasi, demografiunit kendaraan, demografikaryawan, dan laporan laba usaha (setelah pajak)periode 2016 sampai dengan 2018.Adapun untuk data demografi karyawan dapat dilihat pada tabel di bawah ini.

Data primer adalah data yang didapatkan dari pengamatan dan survei kuesioner di lingkungan internal PT. Galena Perkasa Sidoarjo (lingkup karyawan).

\section{Hasil Penelitian}

\section{Pengolahan Data}

Semua proses uji instrumen dalam penelitian ini tidak dilakukan secara perhitungan manual tetapi menggunakan programStatistical Package for The Social Science(SPSS).

\section{Demografi Responden}

Responden dalam penelitian ini adalah semua karyawan PT. Galena Perkasa Sidoarjo yang berjumlah 70 orang. Demografi responden di deskripsikan berdasarkan usia, jenis kelamin, pendidikan terakhir, dan masa kerja karyawan, sesuai tabel di bawah ini.

Tabel 1. Demografi Responden Berdasarkan Usia.

\begin{tabular}{|c|c|c|}
\hline $\begin{array}{c}\text { Usia } \\
\text { (tahun) }\end{array}$ & $\begin{array}{c}\text { Jumlah } \\
\text { (orang) }\end{array}$ & $(\%)$ \\
\hline $21-30$ & 1 & 1 \\
$31-40$ & 23 & 33 \\
$41-50$ & 32 & 46 \\
$51-60$ & 14 & 20 \\
\hline Total & 70 & 100 \\
\hline
\end{tabular}

Tabel 2. Demografi Responden Berdasarkan Masa Kerja.

\begin{tabular}{|c|c|c|}
\hline $\begin{array}{c}\text { MasaKerja } \\
\text { (tahun) }\end{array}$ & $\begin{array}{c}\text { Jumlah } \\
\text { (orang) }\end{array}$ & $(\%)$ \\
\hline$<5$ & 6 & 9 \\
$5 \leq \mathrm{X}<10$ & 29 & 41 \\
$10 \leq \mathrm{X}<15$ & 28 & 40 \\
$15 \leq \mathrm{X}<20$ & 3 & 4 \\
$20 \leq \mathrm{X}<25$ & 4 & 6 \\
\hline Total & 70 & 100 \\
\hline
\end{tabular}


Jurnal Teknologi dan Manajemen Industri, Vol. 5 No. 2, Agustus 2019

Pascasarjana Institut Teknologi Nasional Malang

Tabel 3. Demografi Responden Berdasarkan Pendidikan Terakhir.

\begin{tabular}{|c|c|c|}
\hline PendidikanTerakhir & $\begin{array}{c}\text { Jumlah } \\
\text { (orang) }\end{array}$ & $(\%)$ \\
\hline SMA/SMK & 48 & 69 \\
D3 & 5 & 7 \\
S1 & 17 & 24 \\
$>$ S1 & 0 & 0 \\
\hline Total & 70 & 100 \\
\hline
\end{tabular}

Sumber :data PT. Galena Perkasa Sidoarjo, 2019
Tabel 4. Demografi Responden Berdasarkan Jenis Kelamin.

\begin{tabular}{|c|c|c|}
\hline JenisKelamin & $\begin{array}{c}\text { Jumlah } \\
\text { (orang) }\end{array}$ & $(\%)$ \\
\hline Laki-laki & 62 & 89 \\
Perempuan & 8 & 11 \\
\hline Total & 70 & 100 \\
\hline
\end{tabular}

\section{Hasil Uji Instrumen}

Untuk mengetahui kesesuaian dan konsistensi kuesioner yang dikumpulkan dari responden, maka harus dilakukan uji instrumen terhadap hasil survei tersebut, meliputi uji validitas dan uji reliabilitas terhadap semua butir pertanyaan variabel $\mathrm{X}_{1}, \mathrm{X}_{2}, \mathrm{X}_{3}, \mathrm{X}_{4}, \mathrm{X}_{5}, \mathrm{X}_{6}$, dan $\mathrm{Y}$.

Uji validitas penelitian ini dilakukan dengan cara membandingkan antara nilai setiap butir pertanyaan dengan nilai totalnya per masing-masing variabel BEF dengan menggunakan teknik Pearson Correlation Coefficients. Adapun dasar pengambilan keputusan uji validitas kuesioner, adalah ${ }^{[9]}$ :

1. Membandingkan antara $r_{\text {hasil }}$ dengan $r_{\text {tabel }}$.

- Jika $r_{\text {hasil }}>r_{\text {tabel }}$ maka butir pertanyaan dinyatakan valid.

- Jika $r_{\text {hasil }}<r_{\text {tabel }}$ maka butir pertanyaan dinyatakan tidak valid.

2. Membandingkan nilai Sig. (2-tailed) dengan Probabilitas 0,05

- Jika Sig. (2-tailed) <0,05 maka butir pertanyaan dinyatakan valid.

- Jika Sig. (2-tailed) > 0,05 maka butir pertanyaan dinyatakan tidak valid.

Pada penelitian ini diperoleh $\mathrm{N}=70$, tingkat signifikansi 0,05 dan $\mathrm{r}_{\text {table }}=0,235$ sehingga hasil uji validitas masing-masing butir pertanyaan dalam hasil survei kuesioner dinyatakan valid jika $r_{\text {hasil }}>0,235$ atau Sig. (2-tailed) $<0,05$

Sedangkan untuk uji reliabilitas penelitian inidilakukan dengan cara membandingkan nilai total $\mathrm{X}_{1}, \mathrm{X}_{2}, \mathrm{X}_{3}, \mathrm{X}_{4}, \mathrm{X}_{5}$, dan $\mathrm{X}_{6}$ dengan nilai total $\mathrm{Y}$. Adapun dasar pengambilan keputusan uji reliabilitas kuesioner adalahbutir pertanyaan dikatakan reliabel jika nilai Cronbach Alpha ${ }_{\text {hasil }}>0,60{ }^{[9]} \mathrm{Pada}$ penelitian ini diperoleh kesimpulan bahwa semua variabel bebas BEF memiliki nilai Cronbach Alpha $_{\text {hasil }}>0,60$ sehingga kuesioner dinyatakan reliabel dan cocok untuk digunakan dalam penelitian ini.

\section{Pembobotan Hasil Survei Kuesioner Berdasarkan Kriteria BEF}

Pembobotan hasil survei kuisioner digunakanuntukmengetahuiskor dan tingkatankinerja perusahaan saat ini, dan secaramatematispenghitungan skor BEF padasetiapvariabelbebas dan terikat,diperolehmelaluirumusdi bawah ini ${ }^{[10]}$ :

$$
\text { SkorBEF }=\frac{\left[\sum \frac{\left(\sum_{i} w_{i}\right)}{N W}\right] \times 100 \%}{X} \times \text { skor standar masing-masing kategori variabel }
$$

Keterangan :

$$
\begin{array}{ll}
n_{i}=\text { jumlahpemilihjawabanke }-i & N=\text { total jumlahresponden } \\
w_{i}=\text { bobotjawabanke }-i & W=\text { bobotjawabanterbesar }
\end{array}
$$

$X=$ jumlah total pertanyaan/pernyataanpadatiap

kategorivariabel yang lolosujivaliditas

dengan menggunakan rumusan di atas, selanjutnya dilakukan pembobotan hasil survei kuisioner terhadap masing-masing variabel bebas dan variabel terikat BEF. Berikut di bawah ini contoh hasil pembobotan skor BEF variabel Kepemimpinan. 
Jurnal Teknologi dan Manajemen Industri, Vol. 5 No. 2, Agustus 2019

Pascasarjana Institut Teknologi Nasional Malang

Tabel 5. Pembobotan Kuesioner BEF Variabel $\mathrm{X}_{1}$

\begin{tabular}{|c|c|c|c|c|c|c|c|c|c|c|c|c|c|c|}
\hline \multirow{3}{*}{ Sub Variabel/Dimensi } & \multirow{3}{*}{ Indikator } & \multirow{3}{*}{ Pernyataan } & \multirow{2}{*}{\multicolumn{2}{|c|}{\begin{tabular}{|c|} 
Sangat Baik \\
Bobot $=5$ \\
\end{tabular}}} & \multirow{2}{*}{\multicolumn{2}{|c|}{$\begin{array}{c}\text { Baik } \\
\text { Bobot }=4\end{array}$}} & \multirow{2}{*}{\multicolumn{2}{|c|}{$\begin{array}{c}\text { Cukup } \\
\text { Bobot }=3\end{array}$}} & \multirow{2}{*}{\multicolumn{2}{|c|}{$\begin{array}{c}\text { Kurang } \\
\text { Bobot }=2\end{array}$}} & \multirow{2}{*}{\multicolumn{2}{|c|}{$\begin{array}{c}\begin{array}{c}\text { Sangat } \\
\text { Kurang }\end{array} \\
\text { Bobot }=1\end{array}$}} & \multirow{2}{*}{\multicolumn{2}{|c|}{ Jumlah }} \\
\hline & & & & & & & & & & & & & & \\
\hline & & & jml & $\%$ & jml & $\%$ & jmI & $\%$ & jmI & $\%$ & jml & $\%$ & jml & $\%$ \\
\hline \multirow{3}{*}{ Kepemimpinan senior } & $\begin{array}{l}\text { Visi, Misi dan } \\
\text { Nilai-nilai }\end{array}$ & Butir 1 & 14 & $20 \%$ & 35 & $50 \%$ & 16 & $23 \%$ & 5 & $7 \%$ & 0 & $0 \%$ & 70 & $100 \%$ \\
\hline & \multirow{2}{*}{$\begin{array}{l}\text { Komunikasi dan } \\
\text { kinerja organisasi }\end{array}$} & Butir 2 & 12 & $17 \%$ & 30 & $43 \%$ & 23 & $33 \%$ & 5 & $7 \%$ & 0 & $0 \%$ & 70 & $100 \%$ \\
\hline & & Butir 3 & 10 & $14 \%$ & 32 & $46 \%$ & 22 & $31 \%$ & 6 & $9 \%$ & 0 & $0 \%$ & 70 & $100 \%$ \\
\hline \multirow{5}{*}{$\begin{array}{l}\text { Tata kelola dan } \\
\text { tanggung jawab } \\
\text { Kemasyarakatan }\end{array}$} & \multirow{2}{*}{$\begin{array}{l}\text { Tata Kelola } \\
\text { organisasi }\end{array}$} & Butir 4 & 11 & $16 \%$ & 38 & $54 \%$ & 17 & $24 \%$ & 3 & $4 \%$ & 1 & $1 \%$ & 70 & $100 \%$ \\
\hline & & Butir 5 & 8 & $11 \%$ & 23 & $33 \%$ & 31 & $44 \%$ & 7 & $10 \%$ & 1 & $1 \%$ & 70 & $100 \%$ \\
\hline & \multirow{2}{*}{$\begin{array}{l}\text { Perilaku etis dan } \\
\text { patuh } \\
\text { hukum }\end{array}$} & Butir 6 & 19 & $27 \%$ & 37 & $53 \%$ & 11 & $16 \%$ & 3 & $4 \%$ & 0 & $0 \%$ & 70 & $100 \%$ \\
\hline & & Butir 7 & 18 & $26 \%$ & 40 & $57 \%$ & 10 & $14 \%$ & 2 & $3 \%$ & 0 & $0 \%$ & 70 & $100 \%$ \\
\hline & $\begin{array}{l}\text { Tanggung jawab } \\
\text { sosial dan } \\
\text { mendukung } \\
\text { komunitas kunci }\end{array}$ & Butir 8 & 20 & $29 \%$ & 37 & $53 \%$ & 10 & $14 \%$ & 3 & $4 \%$ & 0 & $0 \%$ & 70 & $100 \%$ \\
\hline & & & 112 & & 272 & & 140 & & 34 & & 2 & & & \\
\hline$N=70$ & \multicolumn{2}{|l|}{$n_{i} w_{i}$} & \multicolumn{2}{|c|}{560} & \multicolumn{2}{|c|}{1088} & \multicolumn{2}{|c|}{420} & \multicolumn{2}{|c|}{68} & \multicolumn{2}{|c|}{2} & & \\
\hline$W=5$ & \multicolumn{2}{|l|}{$\frac{\left(\Sigma n_{i} w_{i}\right)}{N W}$} & & 600 & \multicolumn{2}{|c|}{3,109} & & 200 & \multicolumn{2}{|c|}{0,194} & \multicolumn{2}{|c|}{0,006} & & \\
\hline \multirow[t]{2}{*}{$X=8$} & {$\left[\sum \frac{\left(\sum n_{i} w_{i}\right)}{N W}\right] \mathbf{x}$} & $100 \%$ & \multicolumn{10}{|c|}{6,109} & & \\
\hline & $\frac{\left\{\left[\sum \frac{\left(\sum n_{i} w_{i}\right)}{N W}\right] x\right.}{X}$ & $100 \%\}$ & \multicolumn{10}{|c|}{0,763571429} & & \\
\hline Std Score BEF $=120$ & $\frac{\left\{\left[\sum \frac{\left(\sum n_{i} w_{i}\right)}{N W}\right] \times 100 \%\right\}}{X}$ & $\times 120$ & \multicolumn{6}{|c|}{91,629} & \multicolumn{2}{|c|}{$\approx$} & 92 & & & \\
\hline
\end{tabular}

dengan mekanisme yang sama, maka proses perhitungan di atas diberlakukan juga kepada variabel $\mathrm{X}_{2}$, $\mathrm{X}_{3}, \mathrm{X}_{4}, \mathrm{X}_{5}, \mathrm{X}_{6}$, dan $\mathrm{Y}$ dengan kesimpulan sesuai tabel di bawah ini.

Tabel 6. Hasil Perhitungan Pembobotan Kuesioner Semua Variabel BEF.

\begin{tabular}{|c|c|c|c|}
\hline Variabel & $X$ & $\begin{array}{c}\text { Standar } \\
\text { BEF }\end{array}$ & HasilPerhitungan \\
\hline $\mathrm{X}_{1}$ & 8 & 120 & 92 \\
$\mathrm{X}_{2}$ & 7 & 85 & 66 \\
$\mathrm{X}_{3}$ & 8 & 85 & 59 \\
$\mathrm{X}_{4}$ & 8 & 90 & 65 \\
$\mathrm{X}_{5}$ & 9 & 85 & 62 \\
$\mathrm{X}_{6}$ & 8 & 85 & 64 \\
$\mathrm{Y}$ & 10 & 450 & 342 \\
\hline
\end{tabular}

Sumber :Hasilpenelitian, 2019 (data diolah).

Selanjutnya dibuat tabel pencapaian kinerja berdasarkan nilai yang ada di kolom "Hasil Perhitungan" pada tabel 6 di atas, seperti tabel di bawah ini.

Tabel 7. Pencapaian Kinerja Berbasis Kriteria BEF.

\begin{tabular}{|l|r|r|c|}
\hline \multicolumn{1}{|c|}{$\begin{array}{c}\text { Baldrige Excellence } \\
\text { Framework }\end{array}$} & $\begin{array}{c}\text { Target } \\
\text { Points }\end{array}$ & $\begin{array}{c}\text { Point } \\
\text { Scored }\end{array}$ & $\begin{array}{c}\% \text { of } \\
\text { Total } \\
\text { Points }\end{array}$ \\
\hline 1. Kepemimpinan & 120 & 92 & $77 \%$ \\
2. Strategi & 85 & 66 & $78 \%$ \\
3. Pelanggan & 85 & 59 & $69 \%$ \\
4. Pengukuran, Analisa, & & & \\
danManajemenPengetahua & 90 & 65 & $72 \%$ \\
n & & 62 & $73 \%$ \\
5. TenagaKerja & 85 & 64 & $75 \%$ \\
6. Operasi & 85 & 342 & $76 \%$ \\
7. Kinerja & 450 & $\mathbf{7 5 0}$ & $\mathbf{7 4 \%}$ \\
\hline \multicolumn{1}{|c|}{ Totals } & 1000 & & \\
\hline
\end{tabular}

Sumber :Hasilpenelitian, 2019 (data diolah). 
Tabel 8. Skor dan Kategori Pencapaian Kinerja PT. Galena Perkasa Sidoarjo.

\begin{tabular}{|c|c|c|}
\hline Category & Score & Remark \\
\hline \multirow{5}{*}{ Excellent } & $876-$ & PemimpinKelasDunia(World Class \\
& 1000 & Leader) \\
\cline { 2 - 3 } & $776-$ & Pemimpin Benchmark (Benchmark \\
& 875 & Leader) \\
\cline { 2 - 3 } & $\mathbf{6 7 6 -}$ & \\
& $\mathbf{7 7 5}$ & PemimpinBisnis(Business Leader) \\
\hline \multirow{5}{*}{ Average } & $576-$ & PemimpinBisnisBaru(Emerging \\
& 675 & Business Leader) \\
\cline { 2 - 4 } & $476-$ & KinerjaBaik(Good Performance) \\
\hline \multirow{5}{*}{ Poor } & 575 & PeningkatanAwal(Early \\
\cline { 2 - 3 } & $376-$ & Improvement) \\
\hline & $276-$ & HasilAwal(Early Result) \\
\cline { 2 - 3 } & 375 & PerkembanganAwal(Early \\
& 275 & Development) \\
\hline
\end{tabular}

Sumber :Hasilpenelitian, 2019 (data diolah).

\section{Kesimpulan}

Berdasarkan penelitian yang dilakukan di PT. Galena Perkasa Sidoarjo, bahwa hasil pengukuran menggunakan kriteria BEF atas kinerja perusahaan saat ini sebesar 750 poindengantingkat pencapaian keseluruhan sebesar 74\% yang artinya posisi kinerja perusahaan saat ini berada pada tingkat Pemimpin Bisnis (Business Leader) dengan kategori Unggulan (Excellent).

\section{Daftar Pustaka}

[1] Kaplan, R.S. \& Norton, D.P. 2004. Strategy Maps: Converting Intangible Assets into Tangible Outcomes, Harvard Business School Press, Boston.

[2] National Institute of Standard and Technology (NIST). 2019, Maret 4. website: https://www.nist.gov/news-events/news/2018/12/2019-2020-baldrige-excellence-framework-andcriteria-businessnonprofit-now.

[3] Gaspersz, Vincent. 2011. Sistem Manajemen Kinerja Terintegrasi Balanced Scorecard dengan Malcolm Baldrige dan Lean Six Sigma Supply Chain Management, Jakarta: PT Gramedia Pustaka Utama.

[4] Susanto, Edi. 2017. Analisis Pendekatan Malcolm Baldrige Criteria for Performance Excellence (MBCfPE) Terhadap Kinerja di PT. Kinenta Indonesia, Jurnal Sistem Teknik Industri, vol. 19, issue 1, pp 1-6

[5] Kosasih, Wilson.,Laricha, danHendrawan. 2015. Analisis Sistem Manajemen Mutu dengan Malcolm Baldrige National Quality Award di Perusahaan Global Berstandarisasi ISO 9001: 2008 (Studi Kasus : PT. Zebra Asaba Industries), Program StudiTeknik Industri, Universitas Tarumanegara, Indonesia.

[6] Kuspijani, DR.Ir. Indung Sudarto, MT. 2012. Pengukuran Kinerja Fakultas Teknik Universitas Bhayarngkara Surabaya (Ubhara) dengan Menggunakan Kriteria Malcolm Baldrige, Program Studi Magister Manajemen Teknologi, Jurnal Institut Teknologi Sepuluh Nopember Surabaya, Indonesia. 
[7] Jayamaha, NilalPalitha. Nigel P. Griggdan Robin S. Mann. 2011. Empirical analysis of the Baldrige Criteria as organizational performance measure dan a theoretical model. Measuring Business Excellence Vol. 15 No. 1. Emerald Group Publishing.

[8] Sugiyono. 2006. Statistika untuk Penelitian, cetakan ke-10, Bandung: Alfabeta.

[9] Arikunto, Suharsimi. 2006. Metodelogi Penelitian, Yogyakarta: Bina Aksara.

[10] Irjayanti, M., 2012. Malcolm Baldrige Preliminary Assessment pada PT Perusahaan Gas Negara (Persero), Tbk.,Banking and Management Review, Vol.1 No.1 ISSN : 2252-8520 